\title{
Research on Method of Module Combination for Cultivation of Individualized Engineering Innovation Ability
}

\author{
Wang Lei, Liu Xiang, Cao Jianhua \\ Engineering Training Center \\ Wuhan University of Science and Technology \\ Wuhan, China \\ Wanglei1987@wust.edu.cn
}

\author{
Xia Xuhui* \\ Engineering Training Center, School of Machinery \& \\ Automation \\ Wuhan University of Science and Technology \\ Wuhan, China \\ xiaxuhui@wust.edu.cn
}

\begin{abstract}
Based on analysis of connotation of individualized innovation ability, this paper combs the main influencing factors in cultivation of individualized innovation ability, establishes individualized training module combination index system for innovation ability, and puts forward individualized training module combination ranking method based on Group Analytic Hierarchy Process for engineering training. Finally, practicality and effectiveness of the method are verified with example of training module combination needed by students of Wuhan University of Science and Technology in a major.
\end{abstract}

Keywords-engineering training; individuation; innovation ability; training modules; group analytic hierarchy process

\section{INTRODUCTION}

Engineering training is a preparatory education in higher institutions to cultivate high - quality engineering and technical personnel with engineering quality and innovation ability. In recent years, transformation and upgrading of manufacturing enterprises posts continuous higher requirement for practice ability and innovation ability of engineering students [1] [2]. For engineering training, teaching curriculum and teaching mode should focus on improving students' practical ability, innovation capacity as a premise [3], pay more attention to students' professional differences and individual needs, and carry out personalized innovative talent training. Referring to project teaching mode of innovative talent cultivation in foreign universities[4], engineering training center of Wuhan University of Science and Technology tried to carry out practical teaching model like "open mechanical and electrical integrated engineering training"[5] and "CDIO-based modular training" among some trainees, with a certain training effect achieved. In order to further develop personalized teaching modules for professional/student needs and thus further improve cultivation efficiency of students' individualized practice and innovation ability under the condition of limited time and teachers' team decided by credit system teaching mode[7] in high quality engineering view [6], our engineering training center tried to carry out on-line "demand survey" in virtue of engineering training and teaching service platform, and sorted training module combination based on "multi-expert

Fund projects: Hubei provincial teaching and research project in higher institutions (No. 2015239); Hubei provincial teaching and research project in higher institutions (No. 2015226); 2015 Wuhan University of Science and Technology Teaching and Research Project (No. 2015z002) online training module evaluation" according to the survey results, to provide decision support for formulation of innovation ability training -oriented individualized training module combination scheme by engineering training center.

\section{THE FACTORS THAT AFFECT CULTIVATION OF INDIVIDUALIZED INNOVATION ABILITY}

Innovation ability is the ability to complete innovative activities under the guidance of innovative thinking, and ability to provide new ideas, new theories, new methods and new inventions with social, economic, ecological values in technological and various practical activities. Seen from definition of personality and composition of individual's innovation ability, personality, intelligence, way of thinking and ability of the individual are important elements of individual innovation ability [8]. Therefore, individualized innovation ability is ability appropriate to individual thinking style, knowledge structure, ability and preference, also an important acting point in cultivation of innovation ability for individual needs. The factors that affect cultivation of personalized innovation ability mainly include:

- Relevance of knowledge structure, that is, degree of coincidence between basic knowledge, professional knowledge of course content of teaching module and existing knowledge structure of the trainee.

- Bias in ability cultivation, that is, according to teaching objectives and difficulty of teaching contents, the designed teaching module has different requirements for students' existing ability and different focus for specific ability training of students.

- Development of individual satisfaction, that is, average satisfaction of historical and professional training students for training module, and evaluation on degree of interest by students to be trained based on module introduction. 


\section{MODULE COMBINATION DECISION FOR INDIVIDUALIZED INNOVATION ABILITY TRAINING}

\section{A. Module combination index system for individualized innovation ability training}

On the basis of connotation of individualized innovation ability and analysis result of the influencing factors, this paper establishes module combination index system for individualized innovation ability training by incorporating training equipment and teacher team factors needed by the teaching module, as shown in Table 1.

TABLE I. TRAINING MODULE COMBINATION INDEX SYSTEM

\begin{tabular}{|c|c|c|c|c|}
\hline $\begin{array}{l}\text { Assessmen } \\
\text { t Objective }\end{array}$ & $\begin{array}{r}\text { Evaluatio } \\
\text { Attribute (Le }\end{array}$ & & $\begin{array}{c}\text { Evaluation indicator } \\
\text { (Level 2) }\end{array}$ & \\
\hline \multirow{15}{*}{$\begin{array}{l}\text { Correlation } \\
\text { between } \\
\text { training } \\
\text { module and } \\
\text { individual } \\
\text { demand }\end{array}$} & \multirow{3}{*}{$\begin{array}{l}\text { Knowledge } \\
\text { structure } \\
\text { relevance }\end{array}$} & \multirow{3}{*}{$\mathrm{B}_{1}$} & $\begin{array}{l}\text { Fundamental knowledge } \\
\text { relevance }\end{array}$ & $\mathrm{b}_{11}$ \\
\hline & & & $\begin{array}{c}\text { Professional knowledge } \\
\text { relevance }\end{array}$ & $\mathrm{b}_{12}$ \\
\hline & & & Training objective relevance & $\mathrm{b}_{13}$ \\
\hline & \multirow{5}{*}{$\begin{array}{l}\text { Bias in ability } \\
\text { cultivation }\end{array}$} & \multirow{5}{*}{$\mathrm{B}_{2}$} & Analysis \& design capabilities & $\mathrm{b}_{21}$ \\
\hline & & & Teamwork ability & $\mathrm{b}_{22}$ \\
\hline & & & Innovation ability & $\mathrm{b}_{23}$ \\
\hline & & & Practical operation ability & $\mathrm{b}_{24}$ \\
\hline & & & Personal perseverance & $\mathrm{b}_{25}$ \\
\hline & \multirow{2}{*}{$\begin{array}{c}\text { Student } \\
\text { satisfaction }\end{array}$} & \multirow{2}{*}{$\mathrm{B}_{3}$} & Previous students' satisfaction & $\mathrm{b}_{31}$ \\
\hline & & & Previous students' interest & $\mathrm{b}_{32}$ \\
\hline & \multirow{5}{*}{$\begin{array}{c}\text { Advancement } \\
\text { of module } \\
\text { content }\end{array}$} & \multirow{5}{*}{$\mathrm{B}_{4}$} & Module content innovation & $\mathrm{b}_{41}$ \\
\hline & & & Module content integration & $\mathrm{b}_{42}$ \\
\hline & & & $\begin{array}{c}\text { Advancement of application } \\
\text { equipment }\end{array}$ & $\mathrm{b}_{43}$ \\
\hline & & & $\begin{array}{c}\text { Advancement of application } \\
\text { software }\end{array}$ & $\mathrm{b}_{44}$ \\
\hline & & & Advancement of teaching team & $\mathrm{b}_{45}$ \\
\hline
\end{tabular}

\section{B. Sorting of individualized training module combination}

For module combination decision-making in individualized innovation ability training, the essence is to sort the existing training modules in accordance with its strength in matching with students' individualized requirements based on the combination index system given in Table 1, select the first $n$ modules to be combined to form a training program. In the process of actual decision-making, to reduce subjectivity and bias of single expert decision-making, multi-expert evaluation and decision-making model based on multi-index are often adopted, which belongs to a multi-attribute group decision issue [9]. In this paper, we use group sorting method of expert information post-processing with completely uncertain expert weight to carry out module combination in individualized innovation ability training.

\section{1) Problem hypothesis}

Hypothesis: There are, $n$ modules waiting for selection, the block set is $M=\left\{M_{1}, M_{2}, \ldots, M_{n}\right\}$, each module $M_{i}$ $(\mathrm{i}=1,2, \ldots, \mathrm{n})$ consists of $m$ attributes, attribute set is $\mathrm{B}=\left\{\mathrm{B}_{1}\right.$, $\left.B_{2}, \ldots, B_{m}\right\}$; each attribute $B_{j}(j=1,2, \ldots, m)$ has $q$ attribute measure indexes, and each attribute measure index set is $B_{j}=\left\{b_{j 1}, b_{j 2}, \ldots, b_{j q}\right\}$, of which, there are $t$ qualitative indicators and $q-t$ quantitative indicators.
The decision maker is composed of experts from a number of different fields, the decision set is $E=\left\{E_{1}, E_{2}, E_{s}\right\}$, the weight of the expert Ek is ek, the expert weight vector is $\mathrm{e}=\left(\mathrm{e}_{1}\right.$, $\left.\mathrm{e}_{2}, \ldots, \mathrm{e}_{\mathrm{s}}\right)$.

\section{2) Determination of attribute index information}

\section{a) Determination of attribute index value}

The quantitative indicators in module combination index system for individualized innovation ability training can be directly determined based on data in teaching service platform for engineering training.

For qualitative index in module combination index system of individualized innovation ability training, evaluation expert Ek provides language evaluation value $v_{i_{j h}}^{k} \in V$, evaluation language set $\mathrm{V}=$ \{low, lower, general, high, very high $\}$ of module Mi under the qualitative attribute index $b_{j h}(h=1,2, \ldots, t)$ based on preference for module Mi. To facilitate calculation, language evaluation value of the qualitative index is first quantized into the form of trapezoidal fuzzy number in the interval $[0,1]$, to be recorded as: $\tilde{v}_{i_{j h}}^{k}=\left(v_{i_{j h 1}}^{k}, v_{i_{j h 2}}^{k}, v_{i_{j h 3}}^{k}, v_{i_{j h 4}}^{k}\right)$ which meets that, $v_{i_{j h 1}}^{k} \leq v_{i_{j h 2}}^{k} \leq v_{i_{j h 3}}^{k} \leq v_{i_{j h 4}}^{k}$. And then, center of gravity method is used for defuzzification of fuzzy index value $\tilde{v}_{i_{j h}}^{k}$ to obtain deterministic $\bar{v}_{i_{j h}}^{k}$.

The evaluation result matrix Xk of expert Ek for module $\mathrm{M}_{\mathrm{i}}$ is constructed according to the evaluation result $X_{i_{j f}^{k}}^{k}=\left\{\begin{array}{l}\bar{V}_{i_{j h}}^{k} \text { of } \\ X_{i_{j f}}\end{array}\right.$. expert Ek for module Mi under attribute index $b_{j f}(f=1,2, \ldots, q)$. Where in, $x_{i_{j f}}$ is the identified value provided by teaching service platform for module $\mathrm{M}_{\mathrm{i}}$ under quantitative attribute index $b_{\mathrm{jf}}$.

\section{b) Determination of weight of attribute index}

Expert Ek makes pairwise comparison between measure index bjf of attribute $\mathrm{Bj}$, and gives reciprocal judgment matrix $A_{j}^{k}=\left[a_{j h}^{k}\right]_{q \times q}$ of relative importance of measure index under attribute $\mathrm{B}_{\mathrm{j}}$. Expert Ek makes pairwise comparison between $m$ attributes, and gives reciprocal judgment matrix $A_{j}^{k}=\left[a_{j}^{k}\right]_{m \times m}$ of relative importance of each attribute. By solving eigenvector of each judgment matrix, we can obtain measure index weight vector $w_{j}^{k}=\left(w_{j f}^{k}\right)_{1 \times q}$ and attribute weight vector $W^{k}=\left(W_{j}^{k}\right)_{1 \times m}$ given by expert Ek under attribute $B_{j}$. The consistency of the obtained weight vector is verified by solving random consistency ratio. If there is no satisfactory consistency, the consistency matrix is modified by consistency ratio correction method. By calculating the weight vector satisfying consistency, we can obtain comprehensive weight $\mathrm{W}_{\mathrm{A}}^{\mathrm{k}}=\left(\mathrm{W}_{1}^{\mathrm{k}} * \mathrm{w}_{1}^{\mathrm{k}}, \cdots, \mathrm{W}_{\mathrm{m}}^{\mathrm{k}} * \mathrm{w}^{\mathrm{k}}\right)$ of each attribute measure index of expert Ek evaluation relative to assessment objective A. 


\section{3) Aggregation of group evaluation results}

According to attribute index comprehensive weight vector $W_{A}^{k}$ given by expert Ek and attribute index value matrix $\mathrm{X}^{\mathrm{k}}$ given by expert $\mathrm{E}_{\mathrm{k}}$, evaluation result $Y^{k}=\left(y_{i}^{k}\right)_{1 \times n}=W_{A}^{k} \cdot X^{k}$ of expert Ek is obtained by simple linear weighting method [10].

Because expert weight is completely uncertain, clustering analysis algorithm is used to solve expert weight, that is, weight of decision-making experts is determined according to concentration of individual evaluation results of decision experts, under the principle that the higher the conformity to most evaluation opinions is, the greater the weight of decision experts is, and the more the deviation from mainstream opinions is, the smaller the weight of decision experts is. That is: according to standardized processing results of all experts in vector matrix evaluation $Y=\left[\left(y_{i}^{1}\right)^{T},\left(y_{i}^{2}\right)^{T}, \cdots,\left(y_{i}^{s}\right)^{T}\right]$, and classes constructed by the experts $G_{1}=\left\{E_{1}\right\}, G_{2}=\left\{E_{2}\right\}, \cdots, G_{s}=\left\{E_{s}\right\}$, using the European distance minimum method, $S$ experts are divided into $S(S \leq S)$ categories. Assume that there are $R_{k}$ experts in the category of $E_{k}{ }^{\text {th }}$ expert, and assume that weight of $k^{\text {th }}$ expert is $e_{k}$, then according to the principle of system clustering analysis, we can see that weight $e_{k}$ of expert is proportional to the number of experts $R_{k}$ in the expert class, and the weight of expert ${ }^{E_{k}}$ can be obtained: ${ }_{\mathrm{e}_{\mathrm{k}}}=\mathrm{R}_{\mathrm{k}} / \sum_{\mathrm{k}=1}^{\mathrm{s}} \mathrm{R}_{\mathrm{k}}$.

Using the expert weight vector $e=\left(e_{1}, e_{2}, \cdots, e_{s}\right)$, we can obtain evaluation result of each module group $Z_{i}=\sum_{k=1}^{s} e^{k} y_{i}^{k}$.
According to size sorting of module group evaluation result ${ }{ }_{i}$, the final training module sorting can be obtained.

\section{APPLICATION AND PRACTICE OF TRAINING MODULE COMBINATION \& SORTING METHOD}

Wuhan University of Science and Technology Engineering Training Center currently has a total of 20 training modules available. The top 8 module combinations in index evaluation sorting are selected from 20 modules as training contents for evaluation of professional students.

\section{A. Practice of modular combination method}

Use "engineering training and teaching service platform" independently developed by Wuhan University of Science and Technology, carry out online "previous students' satisfaction survey" and "previous students' interest degree survey" on the 20 training modules, and use mean value of the survey results as index value of $b_{31}, b_{32}$.

Organize module combination assessment expert group consisting of four persons including teaching management leader, training teacher and professional teacher for online rating of qualitative indicators of 20 training modules. Experts are recorded as $E=\left\{E_{1}, E_{2}, E_{3}, E_{4}\right\}$, the weight is pending. According to reciprocal judgment matrix given by the expert, we can obtain comprehensive weight of attribute index given by each expert, as shown in Table 2.

According to attribute index value given by the expert and the obtained attribute index weight, plus quantitative index value in (1), experts' individual evaluation results can be obtained as shown in Table 3. And according to experts' individual decision-making results, expert weight $\mathrm{e}=(0.3,0.3$, $0.3,0.1)$ can be obtained.

TABLE II. COMPREHENSIVE WEIGHT OF ATTRIBUTE MEASURE INDEX

\begin{tabular}{|c|c|c|c|c|c|c|c|c|c|c|c|c|c|c|c|}
\hline & \multicolumn{3}{|c|}{$\mathrm{B}_{1}$} & \multicolumn{5}{|c|}{$\mathrm{B}_{2}$} & \multicolumn{2}{|c|}{$\mathrm{B}_{3}$} & \multicolumn{5}{|c|}{$\mathrm{B}_{4}$} \\
\hline & $b_{11}$ & $b_{12}$ & $b_{13}$ & $b_{21}$ & $b_{22}$ & $\mathrm{~b}_{23}$ & $b_{24}$ & $b_{25}$ & $b_{31}$ & $b_{32}$ & $\mathrm{~b}_{41}$ & $b_{42}$ & $b_{43}$ & $b_{44}$ & $b_{45}$ \\
\hline$E_{1}$ & 0.104 & 0.104 & 0.021 & 0.039 & 0.036 & 0.072 & 0.015 & 0.097 & 0.026 & 0.051 & 0.197 & 0.102 & 0.030 & 0.026 & 0.079 \\
\hline $\mathrm{E}_{2}$ & 0.110 & 0.117 & 0.039 & 0.079 & 0.041 & 0.091 & 0.019 & 0.017 & 0.055 & 0.018 & 0.196 & 0.097 & 0.032 & 0.025 & 0.065 \\
\hline $\mathrm{E}_{3}$ & 0.104 & 0.104 & 0.035 & 0.037 & 0.037 & 0.070 & 0.014 & 0.096 & 0.050 & 0.025 & 0.194 & 0.118 & 0.029 & 0.023 & 0.063 \\
\hline $\mathrm{E}_{4}$ & 0.093 & 0.099 & 0.033 & 0.045 & 0.040 & 0.077 & 0.015 & 0.092 & 0.057 & 0.029 & 0.185 & 0.108 & 0.028 & 0.027 & 0.071 \\
\hline
\end{tabular}

TABLE III. MATRIX OF EXPERT INDIVIDUAL EVALUATION RESULT

\begin{tabular}{|c|c|c|c|c|c|c|c|c|c|c|c|c|c|c|c|c|c|c|c|c|}
\hline & $\mathrm{M}_{1}$ & $\mathrm{M}_{2}$ & $\mathrm{M}_{3}$ & $\mathrm{M}_{4}$ & $\mathrm{M}_{5}$ & $\mathrm{M}_{6}$ & $\mathbf{M}_{7}$ & $\mathrm{M}_{8}$ & $\mathrm{M}_{9}$ & $\mathrm{M}_{10}$ & $\mathbf{M}_{11}$ & $\mathrm{M}_{12}$ & $\mathbf{M}_{13}$ & $\mathrm{M}_{14}$ & $\mathrm{M}_{15}$ & $\mathrm{M}_{16}$ & $\mathrm{M}_{17}$ & $\mathrm{M}_{18}$ & $\mathbf{M}_{19}$ & $\mathrm{M}_{20}$ \\
\hline $\mathrm{E}_{1}$ & 0.052 & 0.052 & 0.052 & 0.010 & 0.094 & 0.052 & 0.052 & 0.052 & 0.076 & 0.052 & 0.076 & 0.076 & 0.076 & 0.094 & 0.052 & 0.052 & 0.076 & 0.094 & 0.094 & 0.094 \\
\hline$E_{2}$ & 0.080 & 0.080 & 0.011 & 0.011 & 0.080 & 0.055 & 0.055 & 0.055 & 0.055 & 0.055 & 0.080 & 0.080 & 0.055 & 0.080 & 0.080 & 0.080 & 0.080 & 0.080 & 0.099 & 0.099 \\
\hline $\mathrm{E}_{3}$ & 0.052 & 0.076 & 0.010 & 0.010 & 0.076 & 0.052 & 0.052 & 0.052 & 0.076 & 0.052 & 0.076 & 0.076 & 0.076 & 0.094 & 0.076 & 0.052 & 0.094 & 0.094 & 0.094 & 0.094 \\
\hline $\mathrm{E}_{4}$ & 0.068 & 0.068 & 0.009 & 0.009 & 0.068 & 0.047 & 0.047 & 0.047 & 0.068 & 0.047 & 0.068 & 0.068 & 0.084 & 0.068 & 0.068 & 0.068 & 0.068 & 0.084 & 0.068 & 0.084 \\
\hline
\end{tabular}




\section{B. Module combination \& sorting results}

According to decision-making weight of the four experts and individual decision-making result of each expert, module group evaluation result of training for students' individual needs and professional needs can be obtained as $\mathrm{Z}=$ $(0.062,0.069,0.023,0.010,0.082,0.052,0.052,0.052,0.069$, $0.052,0.077,0.077,0.071,0.087,0.069,0.062,0.082,0.089$, $0.093,0.094)$. As can be seen from the sorting results, the 2 modules of highly integrated car design and production can best meet the needs of individualized innovation ability training.

The 20 training modules are sorted according to the results of the combination evaluation, in which the first 8 modules are: $M_{20}>M_{19}>M_{18}>M_{14}>M_{17}>M_{5}>M_{11}>M_{12}$.

According to module classification, module sorting and module difficulty, the final individualized training module combination program for innovation ability training is determined, $\mathbf{M}_{20}$ mechanical and electrical integrated car design and production module (20 hours), $\mathbf{M}_{19}$ mechanical unpowered car design and production module (16 hours), M18 electronic design training module ( 8 hours), $\mathrm{M}_{14} 3 \mathrm{D}$ print training module ( 6 hours), $\mathrm{M}_{17} 3 \mathrm{D}$ design training module $(6$ hours), $\mathrm{M}_{5}$ fitter assembly training module (6 hours), $\mathrm{M}_{11} \mathrm{CNC}$ car training module ( 8 hours), $\mathrm{M}_{12} \mathrm{CNC}$ milling training module (6 hours). Service system provides decision support to final development of scientific training programs based on training program formulated by module selection and combination results.

\section{CONCLUSION}

In order to scientifically develop innovative training programs to meet students' individual needs, on the basis of analyzing connotation and influencing factors of individualized innovation ability, this paper puts forward a method of sorting and combining individual training modules based on group analytic hierarchy process (AHP), and establishes training module combination index system consisting of knowledge structure relevance, ability cultivation bias, student satisfaction and advancement of module content. According to the student needs of Wuhan University of Science and Technology in a major, the expert group composed of 4 people of teaching management leader, training teacher and professional teacher are invited to score the optional 20 training modules online.
According to the expert judgment result, module combination of individualized training teaching program that meet needs of the trainees is obtained. The example verifies effectiveness and practicality of combination and sorting method for training modules.

\section{ACKNOWLEDGMENT}

The authors gratefully acknowledge the financial support from the Hubei provincial teaching and research project in higher institutions under No. 2015239 and No. 2015226. It was also supported by Wuhan University of Science and Technology Teaching and Research Project under No. $2015 \mathrm{z} 002$.

\section{REFERENCES}

[1] Y. X. Bai, M. Chen, et al, "Entrepreneurship engineering talent training: engineering entrepreneurship training based on project learning," [J] Res. Higher. Edu. Eng. pp.122-127, Jun 2013

[2] L. H. Wei, H. H. Xu, C. Y. Zhang, et al, "Exploration and practice of open engineering training teaching," Exp. Technol. Manage. vol.32, pp.191-193, Nov. 2015.

[3] H. W. Zheng, Y. R. Zhang, Y. Q. Ma, et al, "Research and exploration of 3D printing laboratory opening model based on innovation ability development," Exp. Technol. Manage. vol.32, pp.159-162, Nov. 2015.

[4] D. B. Zhang, "Characteristics of and Reference to Innovative Talents Training Mode in Foreign Universities,” Edu. Teach. Res. vol.29, pp.1-4 Aug. 2015.

[5] L. Wang, X. H. Xia, X. Liu, et al, "Construction of open electromechanical integrated engineering training system under the view of high quality engineering," Lab. Sci. vol. 16, pp.176-179, Jun. 2013.

[6] G. H. Jin, X. Jin, et al, "Discussion on training mode of engineering talents in independent colleges under the view of high quality engineering," Res. Higher. Edu. Eng. pp.43-47, Feb. 2012.

[7] X. Liu, L. Wang, et al, "Design and thinking of engineering training teaching system under the credit system," Univ. Edu. vol. 15, pp. 113 $114,2014$.

[8] G. D. Zhang, "Promote individualized education and cultivate students' innovation ability," Forum Contemp. Edu. pp. 20-22, Sep. 2008.

[9] A. Relai, B. Aouni and J. M. Martel, "A multi-attribute method for choosing among potential alternatives with ordinal evaluation," Eur. J. Oper. Res., vol.174, pp.360-337, Jan. 2006.

[10] J. Xiong, Y. W. Chen, et al, "A demand priority ranking method based on multi - attribute group decision-making," Syst. Eng, vol.27, pp. 7983, Mar. 2009. 